\title{
EDITORIAL
}

\section{The structure of amyloid filaments in Alzheimer's disease and the unconventional virus infections of the nervous system ${ }^{1}$}

'Amyloid' defines a generic class of polymerized proteins which share the tinctorial characteristics of binding Congo Red in such a manner as to cause negative birefringence of polarized light. Since it is believed that any protein polymer with a high proportion of its secondary structure in the $\beta$-stranded conformation will exhibit such congophilia (Glenner et al. 1972), it is clear that many different proteins will have an amyloidogenic potential. This potential may be expressed if, given an appropriate environment (concentration, ionic strength, $\mathrm{pH}$, etc.), the region of a protein molecule which tends to form $\beta$-sheets (usually an interior region with a series of $\beta$-strands) polymerizes into amyloid fibrils.

The amyloidogenic protein may arise through proteolytic action in which a pre-existing (precursor) molecule is broken down to expose the $\beta$-stranded domains. Alternatively, errors in translation or altered splicing or processing of translation products may give rise to polypeptides which have a strong tendency to form $\beta$-sheet structures.

To date, all of the known amyloid proteins have a fibrillar quaterary structure (typically, fibrils 5-10 $\mathrm{nm}$ in diameter, and of indeterminant length). However, this does not necessarily imply that the tertiary structure is typical of fibrous proteins in general, or that it is a polymer based on the known structure of fibrous cytoskeletal proteins. Structures based on the polymerization of globular subunits must also be considered.

Another important physico-chemical property of the amyloid proteins is their insolubility and stability, probably conferred at least in part by the $\beta$-sheet structure itself. Strong chaotropic ions, harsh denaturants, and extremes of $\mathrm{pH}$ are usually required to make soluble or de-stabilize these proteins. In turn, it is likely that the normal eukaryotic cell has great difficulty in processing these molecules once the subunits have aggregated.

With these general remarks in mind, we can review some recent data in which two of the more important classes of cerebral amyloid proteins have been identified at a molecular level: first, the amyloid proteins in Alzheimer's disease; secondly, the amyloid associated with the unconventional virus diseases (scrapie, kuru, Creutzfeldt-Jakob disease).

In Alzheimer's disease (AD), three forms of amyloid deposits are seen: (i) intracellular neurofibrillary tangles (NFT) composed of paired helical filaments (PHF) which occur within the soma of neurons and also in pre-synaptic axonal terminals; (ii) these neuritic terminals in turn surround extracellular deposits of amyloid plaque cores (APC); (iii) amyloid deposits also accumulate around the walls of small vessels and arterioles to form an amyloid congophilic angiopathy (ACA), some of which clearly show neuritic degeneration surrounding an affected vessel. The pathogenesis of these pathognomonic changes in $\mathrm{AD}$ is uncertain, but it has always been clear that an understanding of the biochemical nature of the amyloid in AD would provide an important clue. Glenner \& Wong (1984) approached this problem by isolating the ACA protein. They found a small polypeptide of about 40 residues $(4 \mathrm{kD})$ and determined the $\mathrm{N}$-terminal sequence of the first 24 amino acids. Our studies (Masters et al. 1985a) were initially directed at the purified APC: we found the same protein subunit (termed $\mathrm{A}_{4}$ ) to be the major constituent of the APC. This protein subunit forms dimers $\left(A_{8}\right)$, tetramers $\left(A_{16}\right)$ and higher aggregates. The $N$-terminal sequence of the APC- $\mathrm{A}_{4}$ closely matched the ACA-A $\mathrm{A}_{4}$, but there was a considerable degree of $\mathrm{N}$-terminal

\footnotetext{
1 Address for correspondence: Dr Colin L. Masters, Neuromuscular Research Institute, Department of Pathology, University of Western Australia, Western Australia 6009. Address for Dr Konrad Beyreuther: Institute for Genetics, University of Cologne, D-5000 Cologne 41, Federal Republic of Germany.
} 
heterogeneity: only $12 \%$ of the protein possessed the full-length chain, and most of the protein (64\%) had lost the first three residues. There was no evidence for glycosylation of the purified protein. The amino acid sequence did not show homology with any other known protein. We also observed that the unusual solubility profile of the aggregated amyloid fibrils bore some resemblance to the chemical inactivation profile of scrapie.

Next, we examined the composition of purified fractions of NFT (Masters et al. 1985b). Remarkably, these too contained the $\mathrm{A}_{4}$ subunit as the major identifiable protein species. The $\mathrm{N}$-terminal region of the NFT- $\mathrm{A}_{4}$ was even more ragged than that of the $\mathrm{APC}-\mathrm{A}_{4}$, which suggested to us that the structural differences between NFT and APC/ACA might be attributable to the $\mathrm{N}$-terminal heterogeneity.

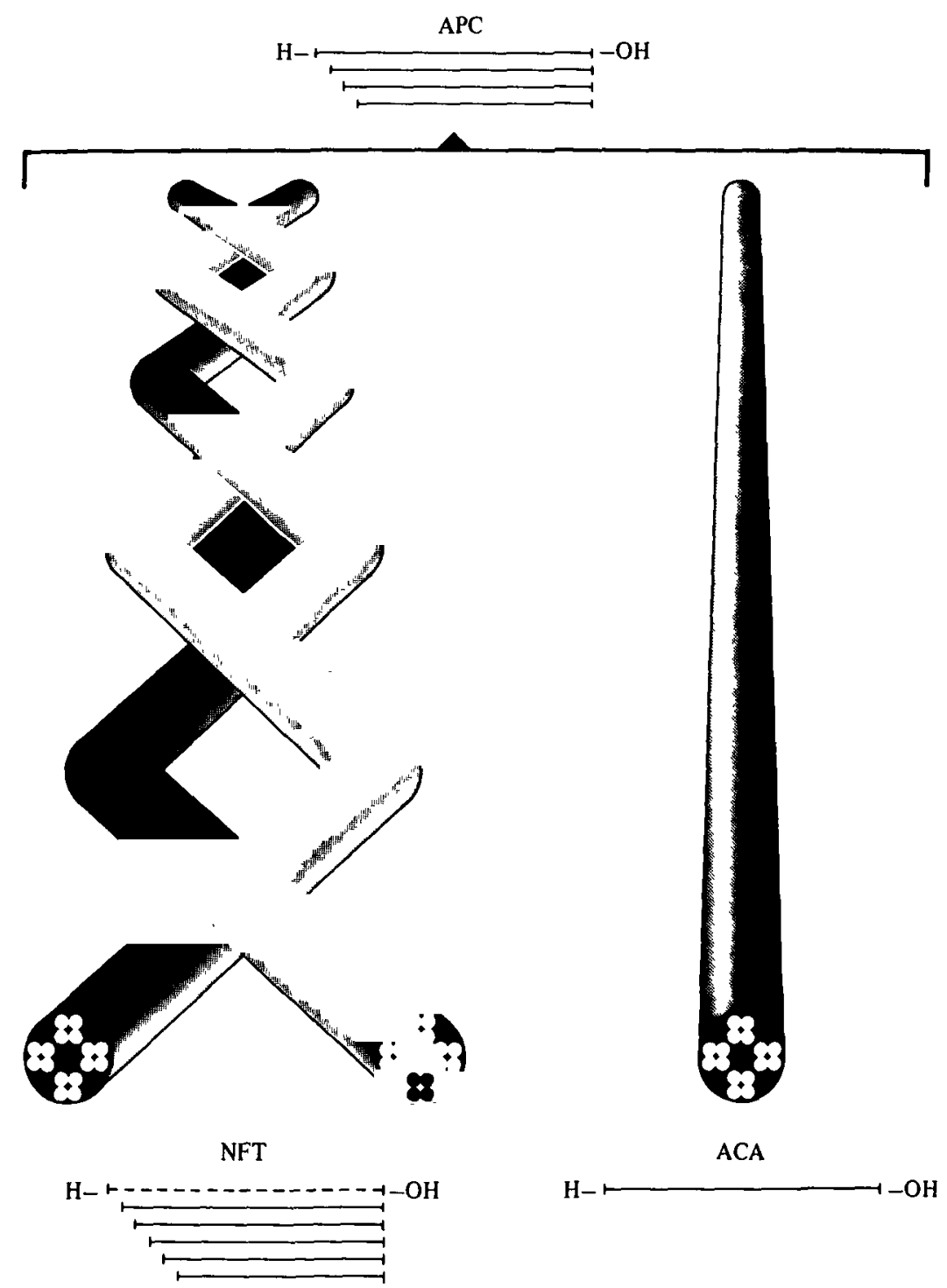

FIG. 1. A schematic representation of the paired helical filament of the neurofibrillary tangle (NFT) and the straight filament constituting the amyloid plaque core (APC) and amyloid congophilic angiopathy (ACA). The relative degrees of $\mathrm{N}$-terminal heterogeneity are shown, with the NFT having the most heterogeneous population. The protein subunits (the $A_{4}$ monomer) are shown as aggregates of four tetramers which together form the structural basis of each filament. 
Through the use of synthetic peptides we have now identified the antigenic epitopes which are shared between NFT and APC/ACA, observing that the N-terminal region is the more important site for the epitopes of NFT.

There is also an inorganic component of the amyloid deposits in AD. Using energy dispersive $\mathrm{X}$-ray analysis, silicon, aluminum, sodium and calcium are identifiable. This inorganic matrix may be in the form of a clay-like montmorillonite which has the idealized formula:

$$
\left(\frac{1}{2} \mathrm{Ca}, \mathrm{Na}\right)_{0 \cdot 33}\left(\mathrm{Al}_{1 \cdot 66} \mathrm{Mg}_{0 \cdot 33}\right)\left[\mathrm{Si}_{4} \mathrm{O}_{10}\right](\mathrm{OH})_{2} \cdot \mathrm{nH}_{2} \mathrm{O} \text {. }
$$

It is, however, unclear whether these inorganic complexes play any role in the formation of the amyloid deposits.

Our present concept of the structure of the different AD amyloid filaments is shown schematically in Fig. 1. This should be compared with a computer-generated model of a double three-stranded ribbon derived from direct imaging studies (Wischik et al. 1985). The final image will, of course, depend on further refinement of both biochemical and structural data.

The fragmented PHF bear a certain resemblance to the scrapie associated fibril (SAF; Merz $e t$ al. 1981). Sequence analysis shows that the protein subunit of the SAF is quite different from $A_{4}$ (Oesch et al. 1985), but that the subunits may share certain biophysical properties (Masters $e t$ al. 1985 a), most important of which is their tendency to self-aggregation. It is now apparent that the protein subunit of the SAF (molecular weight $30-50 \mathrm{kD}$, with glycosylation) is a component of the amyloid plaque cores of scrapie (DeArmond et al. 1985), but it is likely that this protein subunit has undergone some modification (such as cleavage, phosphorylation, etc.) to render it amyloidogenic. The amyloid from scrapie-infected animals has not yet been isolated and characterized in the same way as the $\mathrm{AD}$ amyloid.

There are compelling reasons to suspect that the SAF protein subunit is directly involved with the infectious agent (Oesch et al. 1985), but conclusive evidence has not yet been obtained, largely because of the difficulty in purifying the scrapie agent. Most of the difficulty arises from the aggregational properties of the scrapie virus, properties which we now realize to be similar to those of the AD- $\mathrm{A}_{4}$ subunit (Masters et al. $1985 a, b$ ).

The structures of the amyloid filaments in $\mathrm{AD}$ and in the unconventional virus diseases are therefore based on the polymerization of small protein subunits. The in vivo factors which control the numbers of amyloid filaments are unknown, but are likely to involve the regulation and processing of precursor proteins. Whether these protein subunits are integral components of unconventional infectious particles is the area of most pressing concern.

COLIN L. MASTERS AND KONRAD BEYREUTHER

\section{REFERENCES}

DeArmond, S. J., McKinley, M. P., Barry, R. A., Braunfeld, M. B., McColloch, J. R. \& Prusiner, S. B. (1985). Identification of prion amyloid filaments in scrapie-infected brain. Cell 41, 221-235.

Glenner, G. G. \& Wong, C. W. (1984). Alzheimer's disease: initial report of the purification and characterization of a novel cerebrovascular amyloid protein. Biochemical and Biophysical Research Communications 120, 885-890.

Glenner, G. G., Eanes, E. D. \& Page, D. L. (1972). The relation of the properties of Congo red-stained amyloid fibrils to the $\beta$-conformation. Journal of Histochemistry and Cytochemistry 20, $821-826$.

Masters, C. L., Simms, G., Weinman, N. A., Multhaup, G., McDonald, B. L. \& Beyreuther, K. (1985a). Amyloid plaque core protein in Alzheimer disease and Down syndrome. Proceedings of the National Academy of Science, USA 82, 4245-4249.
Masters, C. L., Multhaup, G., Simms, G., Pottgiesser, J., Martins, R. N. \& Beyreuther, K. (1985b) Neuronal origin of a cerebral amyloid: neurofibrillary tangles of Alzheimer's disease contain the same protein as the amyloid of plaque cores and blood vessels. European Molecular Biology Organization Journal 4, 2757-2763.

Merz, P. A., Somerville, R. A., Wisniewski, H. M. \& Iqbal, K. (1981). Abnormal fibrils from scrapie infected brain. Acta Neuropathologica 54, 63-74.

Oesch, B., Westaway, S., Wälchli, M., McKinley, M. P., Kent, S. B. H., Aebersold, R., Barry, T. A., Tempst, P., Teplow, D. B., Hood, L. E., Prusiner, S. B. \& Weissmann, C. (1985). A cellular gene encodes scrapie PrP 27-30 protein. Cell 40, 735-746.

Wischik, C. M., Crowther, R. A., Stewart, M. \& Roth, M. (1985). Subunit structure of paired helical filaments in Alzheimer's disease. Journal of Cell Biology 100, 1905-1912. 